\title{
Erratum to: Regional citrate anticoagulation for continuous renal replacement therapy in children
}

\author{
Mayerly Prada Rico ${ }^{1}$. Jaime Fernández Sarmiento ${ }^{2}$ Ana María Rojas Velasquez ${ }^{3}$. \\ Luz Stella González Chaparro ${ }^{1}$ - Ricardo Gastelbondo Amaya ${ }^{1}$. \\ Hernando Mulett Hoyos $^{2}$ - Daniel Tibaduiza ${ }^{2}$ - Ana Maria Quintero Gómez ${ }^{1}$
}

Published online: 9 January 2017

(C) IPNA 2016

Erratum to: Pediatric Nephrology

DOI 10.1007/s00467-016-3544-9

In the name Jaime Fernández Sarmiento, "Fernández" is the first element of the author's family name but was incorrectly coded as a second given name in the original publication. This error has since been rectified.

The online version of the original article can be found at http://dx.org.doi/ 10.1007/s00467-016-3544-9.

\section{Jaime Fernández Sarmiento}

JaimeFe@unisabana.edu.co

1 Division of Pediatric Nephrology, Department of Pediatrics,

Fundación Cardioinfantil IC Instituto de Cardiologia,

Bogota, Colombia

2 Division of Pediatric Critical Care, Department of Pediatrics,

Fundación Cardio-infantil IC, Universidad de la Sabana,

Chía, Colombia

3 Division of Pediatric Gastroenterology, Pediatric Gastroenterology, Hepatology and Nutrition UnitGASTRONUTRIPED,

Bogota, Colombia 